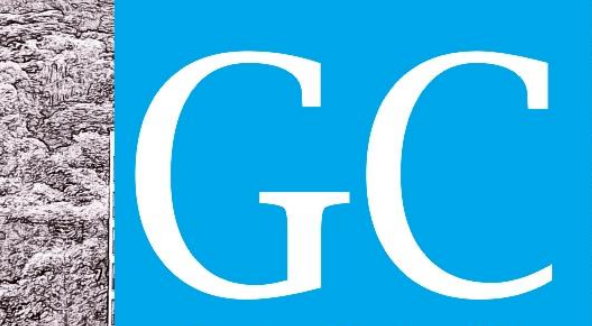

\title{
Desempenho mecânico e térmico de misturas asfálticas do tipo CBUQ com substituição parcial do agregado miúdo por resíduos de polietileno tereftalato (PET)
}

Mechanical and thermal performance of bituminous asphalt concrete with partial replacement of fine mineral aggregate by polyethylene terephthalate waste (PET)

Rendimiento mecánico y térmico de mezclas de asfalto del tipo CBUQ con reemplazo parcial del agregado fino por residuos de tereftalato de polietileno (PET)

Camila Raia Santos Bastos

Engenheira Civil, UFMT, Brasil camilaraia1@gmail.com

Ivan Julio Apolonio Callejas Professor Doutor, UFMT, Brasil Ivancallejas1973@gmai.com

\section{Carol Cardoso Moura Cordeiro}

Professora Mestre, UFMT, Brasil. carolcardoso.eng@gmail.com

\section{Luciane Cleonice Durante}

Professora Doutora, UFMT, Brasil. carolcardoso.eng@gmail.com 
Revista Nacional de Gerenciamento de Cidades

\section{RESUMO}

Esta pesquisa visa avaliar o desempenho térmico de misturas asfálticas de Concreto Betuminoso Usinado à Quente (CBUQ) com substituição parcial do agregado miúdo por flakes de PET. Foi moldado um corpo de prova com o traço convencional de CBUQ (32,5\% de brita 1, 28\% de pedrisco, 32,5\% de pó de pedra e $7 \%$ de Cimento Asfáltico de Petróleo - CAP - 30/45) e mais três corpos de prova, nos quais substituiu-se o pó de pedra por flakes de PET passantes na peneira de $4,8 \mathrm{~mm}$, nos teores de $5 \%, 10 \%$ e 15\%. Realizaram-se ensaios mecânicos de estabilidade, fluência e resistência à tração e o comportamento térmico das misturas foi avaliado por meio de medições de temperatura superficial nas faces superior e inferior dos corpos de prova. Os resultados evidenciaram que a adição de flakes de PET em até $5 \%$ influenciou positivamente no desempenho térmico das misturas.

PALAVRAS-CHAVE: Resíduos sólidos. Sustentabilidade urbana. Condutividade térmica.

\section{ABSTRACT}

The aim of this research was to evaluate the thermal performance of bituminous asphalt concrete with partial replacement of fine mineral aggregate with partial replacement of the small aggregate by PET flakes. The conventional trait of bituminous asphalt concrete consisted of $32.5 \%$ of crushed stone, $28 \%$ of small stones, $32.5 \%$ of stone dust, and $7 \%$ of petroleum asphalt cement (PAC) 30/45, and for the other traces the stone dust was replaced by PET flakes passing through the sieve of $4.8 \mathrm{~mm}$, in the contents of $5 \%, 10 \%$ and $15 \%$. Mechanical tests of stability, creep and tensile strength were performed and the thermal behavior of the mixtures was evaluated by surface temperature measurements on the upper and lower faces of the specimens. The results showed that the addition of PET flakes up to $5 \%$ positively influenced the thermal performance of the blends.

KEYWORDS: Solid waste, Urban Sustainability, thermal conductivity.

\section{RESUMEN}

Esta investigación tiene como objetivo evaluar el rendimiento térmico de las mezclas de asfalto de hormigón bituminoso mecanizado en caliente con reemplazo parcial del agregado fino por escamas de PET. Se moldeó una muestra con la traza convencional de CBUQ (32.5\% de piedra triturada 1, 28\% de grava, 32.5\% de polvo de piedra y $7 \%$ de Asphalt Petroleum - CAP - 30/45) y tres muestras más, en las cuales el polvo de piedra fue reemplazado por escamas de PET que pasaron a través del tamiz de $4.8 \mathrm{~mm}$, en contenidos de 5\%, 10\% y 15\%. Se llevaron a cabo pruebas mecánicas de estabilidad, fluencia y resistencia a la tracción y se evaluó el comportamiento térmico de las mezclas mediante mediciones de temperatura superficial en las caras superior e inferior de las muestras. Los resultados mostraron que la adición de escamas de PET hasta en un 5\% influyó positivamente en el rendimiento térmico de las mezclas.

PALABRAS CLAVE: Residuos sólidos. Sostenibilidad urbana. Conductividad térmica. 


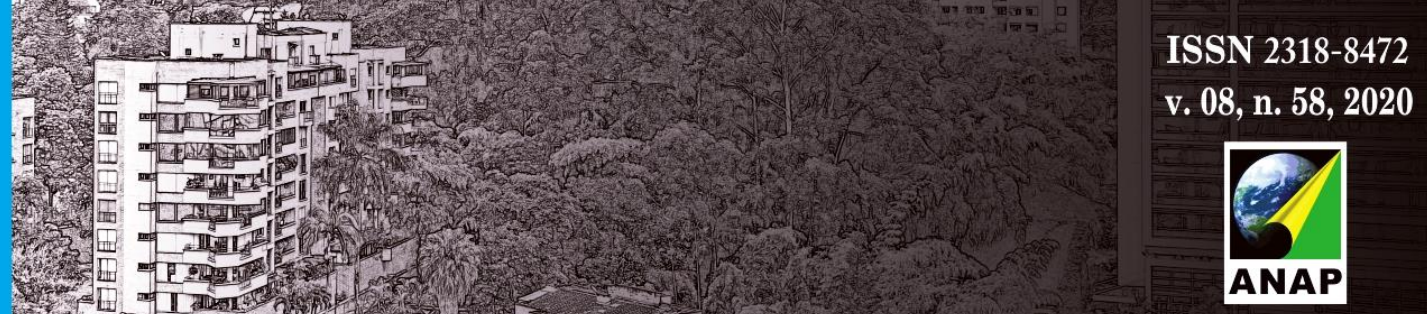

Revista Nacional de

Gerenciamento de Cidades

\section{INTRODUÇÃO}

A urbanização modifica e fragmenta a paisagem natural e a geometria dos centros urbanos, substituindo vegetação e solo por construções e pavimentos, alterando as propriedades térmicas da atmosfera e contribuindo com o aquecimento e formação das Ilhas de Calor Urbana (ICU) (AMORIM, 2017).

O revestimento asfáltico, amplamente utilizado nas cidades, favorece consideravelmente a formação desses fenômenos pois, devido à cor escura, absorve cerca de $80 \%$ da radiação solar incidente e, também, irradia mais calor. Nesse sentido, a busca por um revestimento asfáltico que mantenha suas propriedades mecânicas, imprescindíveis ao tráfego urbano de veículos e que minimize os problemas térmico ambientais decorrente de seu uso, encontram justificativa, principalmente, em regiões de clima quente (CALLEJAS; DURANTE; ROSSETI, 2015).

Pesquisas recentes relacionam a incorporação de polietileno tereftalato (PET) em materiais de construção e o comportamento térmico. O Conselho Nacional de Pesquisa Científica (CONICET) da Argentina desenvolveu placas de concreto não estruturais incorporando resíduos de garrafas PET, o que aumentou a capacidade de isolamento térmico em, aproximadamente, cinco vezes. Incorporado em tijolos, o PET possibilitou melhora na capacidade de isolamento térmico e redução da densidade do material (GAGGINO et al., 2015).

Existem estudos que incorporaram PET a materiais de pavimentação com foco no desempenho mecânico, comprovando a viabilidade do uso como material alternativo em misturas asfálticas, sem comprometer a eficácia das propriedades mecânicas do pavimento. Dentre esses, cita-se Moghaddam e Karim (2012), que avaliaram a influência mecânica da adição de PET com diâmetro máximo de 2,36 mm, nos teores de 0,2\%, 0,4\%, 0,6\%, 0,8\% e 1,0\% de misturas asfálticas do tipo Stone Mastic Asphalt (SMA). Os autores verificaram o aumento da estabilidade e fluência, com melhor resultado para estabilidade no traço com 0,4\% de PET.

Almeida e Silva (2015) propuseram a incorporação de PET em proporções de 4\%, 5\% e 6\% relativas ao peso do teor de Cimento Asfáltico de Petróleo (CAP). Os resultados indicaram que o resíduo do PET micronizado no teor de $5 \%$ pode ser utilizado como agente modificador do CAP, sendo o mesmo capaz de promover ganhos nas propriedades mecânicas de revestimentos asfálticos. Arao (2016) verificou que a adição de resíduos de PET em revestimentos asfálticos a quente promoveu melhoras no desempenho mecânico deste material. A adição de $1 \%$ de PET de $2 \mathrm{~mm}$ aumentou em $16 \%$ a estabilidade e $35 \%$ a resistência a tração em relação a mistura asfáltica convencional. Serra et al. (2018) também avaliaram o comportamento de misturas asfálticas usinadas a quente com substituição parcial do agregado miúdo com a incorporação de PET nas proporções de $1 \%, 2 \%$ e $3 \%$. A pesquisa indicou que a adição de material PET é satisfatória quando adicionado a baixas porcentagens.

Räder et al. (2018) analisaram as propriedades de misturas asfálticas modificadas com teores de $0,7 \%$ e $1,5 \%$ de resíduos provenientes da moagem de garrafas PET, em pó e em flake, em substituição de uma fração do agregado miúdo, concluindo que as misturas com $0,7 \%$ do resíduo apresentaram melhores resultados e aplicação em pavimentação. 


\section{Revista Nacional de}

\section{OBJETIVOS}

Esse estudo visa avaliar experimentalmente se a substituição de parte dos agregados miúdos do Concreto Betuminoso Usinado a Quente (CBUQ) por resíduos de reciclagem de garrafas PET (flakes) proporciona melhoria das propriedades térmicas, mantendo as propriedades mecânicas nos limites estabelecidos pelas normas técnicas. $O$ estudo, que se fundamenta nas potenciais contribuições para melhoria do ambiente térmico urbano, agrega valor sustentável ao propor a utilização de resíduos de PET tendo em vista que, tal qual a maioria dos plásticos, esse polímero causa prejuízos ao meio ambiente quando descartado na natureza, uma vez que seu processo de decomposição é longo e de elevado impacto global.

\section{MÉTODO DE ANÁLISE}

Para a composição do CBUQ, foi utilizado Cimento Asfáltico de Petróleo (CAP) 30/45; agregados provenientes de empresas do município de Cuiabá-MT: brita 1; pedrisco; pó de pedra; e, flakes de PET passantes na peneira de malha $4,8 \mathrm{~mm}$. Utilizaram-se quatro traços de $C B \cup Q$, sendo um deles o de referência, sem adição de PET, denominado T1. Nos demais traços foram adicionados os flakes de PET em substituição ao agregado miúdo (pó de pedra), com quantidades de $5 \%$, $10 \%$ e $15 \%$, respectivamente, em massa, doravante denominados T2, T3 e T4. Todos os procedimentos foram realizados em concordância com as condições estabelecidas pela norma técnica DNIT 031/2006, que trata de pavimentos flexíveis, nos ensaios abaixo relacionados.

Os equipamentos e procedimentos metodológicos são: Caracterização dos materiais utilizados na pesquisa; Enquadramento da granulometria dos agregados em uma das faixas estabelecidas por DNIT 031/ 2006; Determinação do teor ótimo de ligante no traço convencional do CBUQ; Confecção de corpos de prova nos seguintes traços: T1 - CBUQ convencional; T2 - CBUQ com substituição parcial de $5 \%$ de pó de pedra por flakes de PET; T3 - CBUQ com substituição parcial de $10 \%$ de pó de pedra por flakes de PET; T4 - CBUQ com substituição parcial de $15 \%$ de pó de pedra por flakes de PET; e, Realização dos ensaios mecânicos e térmicos.

\subsection{ENSAIOS DE CARACTERIZAÇÃO E MECÂNICOS}

Realizou-se a amostragem dos materiais com auxílio de um separador mecânico. Para a determinação da composição granulométrica dos materiais pétreos e flakes de PET, seguiramse os procedimentos experimentais especificados na NBR NM 248 (ABNT, 2003), utilizando a série de peneiras da norma técnica DNIT 031/2006.

A massa específica real dos materiais, necessária para a dosagem do teor ótimo de asfalto para o CBUQ, foi determinada segundo a NBR NM 53 (ABNT, 2002) e NBR NM 52 (ABNT, 2002). Para 


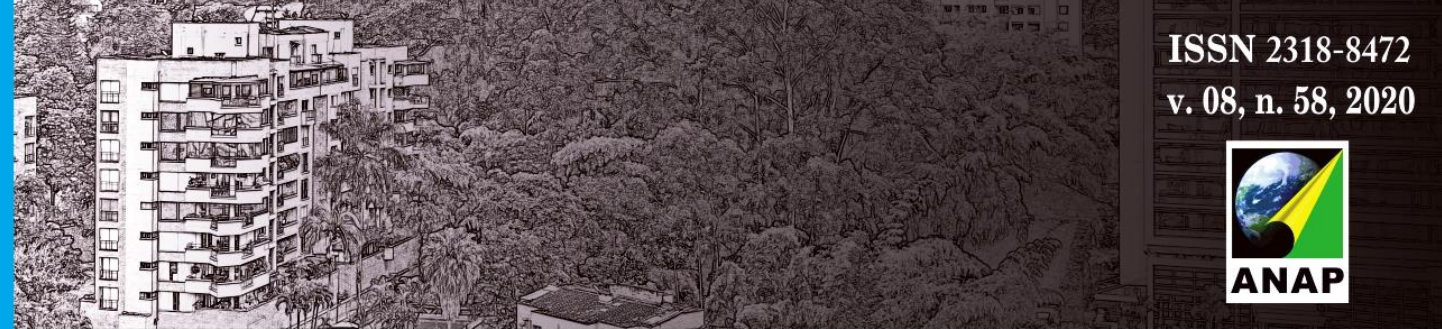

\section{Revista Nacional de}

Gerenciamento de Cidades

os flakes de PET, aplicou-se mesmo método especificado para o agregado miúdo, utilizando picnômetros. Para que agregados graúdos possam ser utilizados em pavimentos flexíveis, a abrasão dos grãos deve ser inferior a $50 \%$, portanto foram seguidos os procedimentos estabelecidos na NBR NM 51 (ABNT, 2001). O índice de forma dos agregados graúdos, relação entre o comprimento e a largura de seus grãos, foi determinado pelo método do paquímetro, conforme NBR 7809 (ABNT, 2006). Por fim, o ensaio de equivalente de areia, que avalia a quantidade e a qualidade de elementos finos plásticos presentes na amostra, foi realizado apenas para o pó de pedra, não sendo aplicável aos flakes de PET. Seguiu-se a metodologia especificada da norma técnica DNER-ME 054/1997.

O ligante asfáltico do tipo CAP 30/45 foi caracterizado de acordo com os parâmetros estabelecidos por DNIT 031/2006. Realizou-se primeiramente o ensaio de penetração, que determina quantos milímetros uma agulha padrão penetra no material betuminoso em condições estabelecidas por DNER-ME 003/1999. Para o CAP 30/45, o valor esperado deve estar entre $30 \mathrm{~mm}$ e $45 \mathrm{~mm}$. Optou-se pela determinação da viscosidade por meio do viscosímetro Brookfield, seguindo-se as orientações da NBR 9277 (ABNT, 2014). A determinação da massa específica real seguiu as recomendações da NBR 6296 (ABNT, 2012). Esse ensaio é semelhante ao de determinação da massa específica dos agregados miúdos, pois utiliza um picnômetro para a pesagem seca e submersa dos materiais, para posterior cálculo da densidade. Para a compactação dos corpos de prova, fixou-se a massa de agregados por mistura em $1100 \mathrm{~g}$, seguindo a composição granulométrica de cada traço. Após mistura manual, foi feita a moldagem, com compactação de acordo com DNER-ME 043/1995.

A dosagem da mistura, que consiste na determinação da composição granulométrica e do teor de asfalto ótimo da mistura, foi realizada a partir dos parâmetros volume de vazios ( $\mathrm{VV}$ ) e relação betume-vazios (RBV), conforme DNER-ME 043/1995. O ensaio Marshall foi realizado segundo especificações de DNER-ME 043/1995. Os corpos de prova foram medidos e pesados para obtenção dos parâmetros volumétricos e rompidos para determinação da estabilidade e fluência à temperatura de $60^{\circ} \mathrm{C}$. O ensaio de determinação da resistência a tração por compressão diametral foi segundo a NBR 15087 (ABNT, 2012). Utilizou-se a prensa Marshall com o corpo de prova encaixado em um molde de placas paralelas.

\subsection{ENSAIOS TÉRMICOS}

Por meio do uso da primeira Lei da Termodinâmica (Lei de Conservação de Energia), a partir de um volume de controle é possível computar os ganhos, as perdas e o armazenamento de energia em um dossel urbano, utilizando-se a Equação 1:

$$
Q^{*}+Q_{F}=Q_{H}+Q_{E}+\Delta Q_{S}+\Delta Q_{A}
$$

em que: Q*: o saldo de radiação líquida; QF: o fonte de calor antropogênica introduzida no volume de controle; $\mathrm{QH}$ : o fluxo de calor sensível turbulento transferido para o ar; QE: o fluxo de calor latente turbulento utilizado para evaporar água dentro do sistema; $\triangle Q S$ : o fluxo 


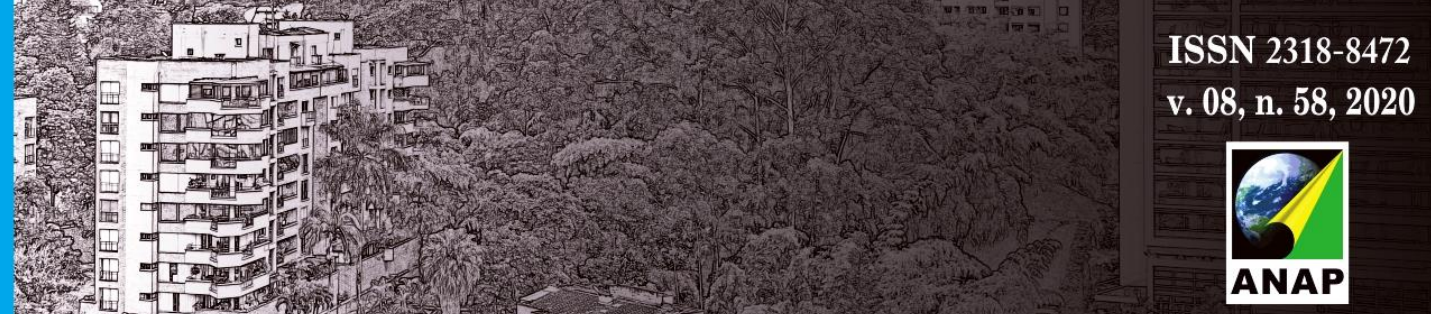

Revista Nacional de

Gerenciamento de Cidades

infravermelha emitida pela superfície dos objetos e a converte em pulsos elétricos, criando imagens térmicas do campo de temperatura (BARREIRA; FREITAS, 2007).

O aparelho utilizado para a medição da temperatura foi uma câmera da marca FLIR. O valor utilizado para a emissividade dos revestimentos asfálticos no aparelho foi o de 0,95. A emissividade mede a razão entre a taxa de radiação emitida por uma superfície e a taxa de radiação emitida por um corpo negro, à mesma temperatura (ABNT, 2003).

Para a determinação da temperatura superficial dos corpos de prova, foram extraídas imagens térmicas horárias da face superior e inferior da placa, sempre posicionando a câmera a uma altura padrão de um metro. Para avaliação da temperatura da face inferior dos corpos de prova, a placa foi momentaneamente virada para cima para realização do procedimento.

As medições foram realizadas de hora em hora, entre $8 \mathrm{~h} 30$ e $16 \mathrm{~h} 30$, no mês de fevereiro (GMT4 , horário de verão). Com vista a estimar os fluxos condutivos transferidos e armazendos em cada um dos traços pesquisados, utilizou-se os dados de temperatura do ar, umidade do ar e radiação solar de uma estação metereológica fixa, no mesmo local.

A leitura dos dados de temperatura superficial foi feita pelo software disponibilizado pelo site do desenvolvedor da câmera (FLIR Tool). A determinação da temperatura superficial média foi feita tomando-se toda a área do corpo de prova nas faces superior e inferior para cada traço.

\subsubsection{Fluxo de calor conduzido nos revestimentos}

A transferência de calor por unidade de área pode ser derivada pela Lei de Fourier, segundo a qual o fluxo de calor por uma barra cilíndrica (ou em corpo de prova cilíndrido) é diretamente proporcional à sua condutividade térmica e inversamente proporcional ao seu comprimento (BERGMAN et al., 2014) conforme Equação 2.

$$
Q \times / A=k .(\Delta T / L)
$$

em que Qx: o calor medido [J/s]; A: a área da seção transversal da barra $\left[\mathrm{m}^{2}\right]$; $\mathrm{k}$ : o coeficiente de condutividade térmica do material avaliado $[\mathrm{Wm}-1 \mathrm{~K}-1], \Delta \mathrm{T}$ : a diferença de temperatura entre as extremidades da face do corpo de prova [K]; L: o comprimento da barra [m].

Uma vez que as superfícies lateral e inferior dos corpos de provas não foram isoladas termicamente e nem os coeficientes de condutividade térmica foram determinados nas amostras pesquisadas, o respectivo fluxo Qx não é passivel de ser estimado. No entanto, como os corpos de prova permaneceram no mesmo ambiente e sujeitos praticamente às mesmas trocas térmicas por conveção e irradiação, trabalhou-se com a variação térmica de temperatura entre as faces, o que permite estimar como a condutividade térmica variou nas amostras com a adição dos flakes de PET. 


\section{Revista Nacional de}

\subsubsection{Estimativa do fluxo de calor armazenado dentro dos traços pesquisados - $\Delta Q S$}

O fluxo de calor armazenado ( $\triangle Q S$ ) é um termo significativo no balanço de energia de superfícies urbanas, e consideravelmente maior do que para a maioria dos sistemas naturais, com exceção da água, atingindo valores que variam de $150 \mathrm{Wm}-2$ a $300 \mathrm{Wm}-2$, correspondendo a até $50 \%$ do valor do saldo de radiação solar em áreas centrais da cidade. É um importante parâmetro para avaliar o desempenho térmico dos pavimentos urbanos, além de influenciar na percepção térmica dos pedestres que trafegam sobre os mesmos e de constribuir consideravelmente na formação de ICU (CALLEJAS et al., 2019).

Utilizou-se o Esquema de Massa Térmica (Thermal Mass Scheme - TMS) derivado dos conceitos básicos da condução de calor e do calor volumétrico armazenado dentro dos materiais, no qual se utiliza de propriedades térmicas e geométricas para se fazer a estimação desta propriedade (MEYN e OKE, 2009).

Assim, o revestimento asfáltico foi tratado como um material homogêneo e o fluxo de calor armazenado por condução térmica foi determinado por meio da variação horária da temperatura interna dos corpos de prova (estimada por meio da média das temperaturas superficiais superior e inferior registradas nas faces) (Equação 3).

$$
\Delta Q_{s}=\sum_{i=1}^{n} \Delta Q_{s i}=\sum_{i=1}^{n} \frac{1}{A_{i}} \int c_{i} \frac{\Delta T}{\Delta t} d m_{i}
$$

em que i: índice que define o número de superfícies dentro do volume de controle (no caso apenas uma para o revestimento asfáltico); $A_{\mathrm{i}}$ : área da superfície de cada componente i do sistema (área total do corpo de prova) $\left[\mathrm{m}^{2}\right] ; \mathrm{c}_{\mathrm{i}}$ : calor específico de cada componente dos materiais i (para o revestimento asfáltico adotou-se o valor igual a 1,034 $\left[\mathrm{kJ} \mathrm{kg}^{-1} \mathrm{~K}^{-1}\right]$ (SPECHT, BORGES; HELLMANN, 2008); $\Delta \mathrm{T} / \Delta \mathrm{t}$ : taxa de mudança de temperatura que acontece em cada componente i dentro do volume de controle por intervalo de tempo (diferença de temperatura nos corpos de prova registrada ao longo das medições); $d_{m i}$ : massa de cada componente $i$ (derivada a partir do valor médio de densidade específica aparente de cada traço e admitindose o volume padrão do corpo de prova testado) $[\mathrm{kg}]$. Os corpos de prova ficaram envoltos no ar (condição distinta de quando estão aplicados em campo), acarretando trocas térmicas por irradiação e convecção, não sendo estas estimadas nesta pesquisa.

\subsubsection{Estimativa da sensação térmica predita por meio do índice térmico UTCI}

Os índices térmicos desenvolvidos permitem a estimação da sensação térmica por meio de modelos termofisiologicos, os quais procuram traduzir a influência das variáveis meteorológicas, fisiológicas (taxa metabólica) e individuais (ajustamento de roupa). Entre os mais utilizados esta o Índice Térmico Climático Universal (UTCI), que apresenta como resposta a temperatura do ar 


\section{Revista Nacional de}

$2,61 \mathrm{~g} / \mathrm{cm}^{3}$ e equivalente de areia de $72 \%$. Os flakes de PET apresentaram massa específica de $1,41 \mathrm{~g} / \mathrm{cm}^{3}$.

O ligante asfáltico utilizado na pesquisa, CAP 30/45, enquadrou-se nos limites estabelecidos pela Agência Nacional de Petróleo (ANP, 2005) quanto aos itens Penetração $(34 \mathrm{~mm})$, Densidade real $\left(1,01 \mathrm{~g} / \mathrm{cm}^{3}\right)$ e Viscosidade Broofkfild $\left(135^{\circ} \mathrm{C}\right.$, SP 21, $20 \mathrm{rpm}-382 \mathrm{cP} ; 150^{\circ} \mathrm{C}, \mathrm{SP} 21,20 \mathrm{rpm}-$ $231 \mathrm{cP} ; 177^{\circ} \mathrm{C}$, SP 21, $\left.50 \mathrm{rpm}-127 \mathrm{cP}\right)$.

De acordo com DNER-ME 043/1995, a temperatura ideal de mistura é aquela em que a viscosidade do ligante asfáltico atinge $170 \mathrm{cP}$. Assim, traçou-se uma curva viscosidadetemperatura, por meio da qual obteve-se a temperatura de $150^{\circ} \mathrm{C}$ como a ideal para a mistura do CBUQ. Ainda de acordo com essa norma, a temperatura determinada para os agregados foi de $165{ }^{\circ} \mathrm{C}$ e de compactação foi de 140 ㄷ. .

$\mathrm{O}$ traço de referência (T1) e os demais traços foram enquadrados granulometricamente na faixa C (DNIT 031, 2006). Para a determinação do teor ótimo, foram testados cinco traços variandose o teor de CAP. A partir dos valores encontrados, verificou que o intervalo aceitável de teor de CAP para a faixa granulométrica adotada é entre $6,72 \%$ e 7,48\%. A partir dos valores máximos e mínimos de Vv e RBV, obteve-se o teor ótimo de CAP correspondente a 7,06\%. Desta forma, optou-se então por utilizar o teor de 7,1\% de CAP para todas as misturas asfálticas produzidas nesta pesquisa. Os resultados do ensaio Marshall com os corpos de prova a $60^{\circ} \mathrm{C}$ encontram-se na Tabela 1.

Tabela 1: Ensaio Marshall

\begin{tabular}{l|lllll}
\hline Traço & T1 & T2 & T3 & T4 & Limites \\
& (Referência) & $\mathbf{( 5 \% ~ P E T ) ~}$ & $\mathbf{( 1 0 \% ~ P E T ) ~}$ & (15\% PET) & \\
\hline DMT (g/cm $\mathbf{3})$ & 2,41 & 2,38 & 2,35 & 2,32 & - \\
Gmb (g/cm $\mathbf{3})$ & 2,32 & 2,26 & 2,15 & 2,08 & - \\
Vv & $3,8 \%$ & $5,0 \%$ & $8,4 \%$ & $10,5 \%$ & $3 \%-5 \%$ \\
VAM & $20,0 \%$ & $21,3 \%$ & $24,5 \%$ & $26,6 \%$ & $14 \%$ \\
RBV & $81 \%$ & $77 \%$ & $66 \%$ & $60 \%$ & $75 \%-82 \%$ \\
Fluência (mm) & 8,1 & 8,9 & 11,8 & 13,9 & - \\
Estabilidade (kgf) & 892 & 632 & 565 & 526 & mín 500 \\
\hline
\end{tabular}

Pela análise estatística dos dados, concluiu-se que, como o coeficiente de variação é inferior a $20 \%$ para todas as amostras, sendo, portanto, considerados homogêneos. Observa-se que todos os traços atingiram a estabilidade mínima exigida pela norma DNER 031/2006. Entretanto, os traços T3 e T4 ultrapassaram o limite máximo de Vv e não alcançaram a RBV de $75 \%$. Isso ocorreu em virtude de o PET triturado aumentar a área superficial dos agregados, o que dificulta o recobrimento pelo ligante, gerando mais vazios na mistura (MARQUES, 2014). O traço T2 com $5 \%$ de incorporação foi o único que atendeu aos requisitos normativos para utilização nas misturas asfálticas, ratificando os achados de Almeida e Silva (2015).

A fluência para os traços T3 e T4 aumentou $50 \%$ e $75 \%$, respectivamente, em relação ao traço de referência, o que se mostra desfavorável, pois a deformação excessiva do CBUQ pode 


\section{Revista Nacional de}

provocar patologias no pavimento. Foi possível também verificar visualmente que, de forma geral, os corpos de provas confeccionados com o traço T4 apresentaram maiores alturas do que os corpos de provas do traço T1, para massas aproximadamente iguais. Portanto, o traço T4 possui menor grau de compactação que o T1.

\subsection{ENSAIO TÉRMICO}

Por não atenderem aos parâmetros mínimos de Vv e RBV estabelecidos no ensaio Marshall, os traços T3 e T4 foram invalidados e, em razão disso, optou-se por não realizar ensaios térmicos nesses corpos de prova. A temperatura ambiente durante a realização do ensaio térmico variou de $29^{\circ} \mathrm{C}$ e $34^{\circ} \mathrm{C}$. Durante as duas primeiras horas do ensaio, observou-se que a temperatura na face superior dos corpos de prova era decrescente entre os traços T1 a T2 (

Figura 3). O desvio padrão ( $\sigma$ ) das medições de temperatura foi baixo, com coeficientes de variação (CV) inferiores a 5\%, o que mostra elevada homogeneidade nas amostras ensaiadas.

Figura 3: Medição de temperatura: (a) Corpo de prova no software FLIR tool (b) Termograma dos corpos de prova T1, T2, T3 e T4 - 10h30min

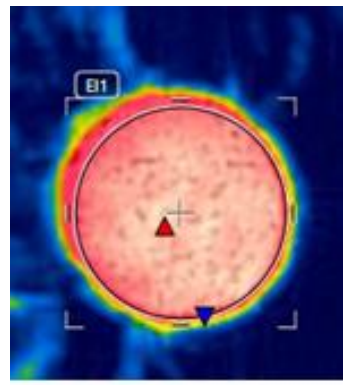

(a)

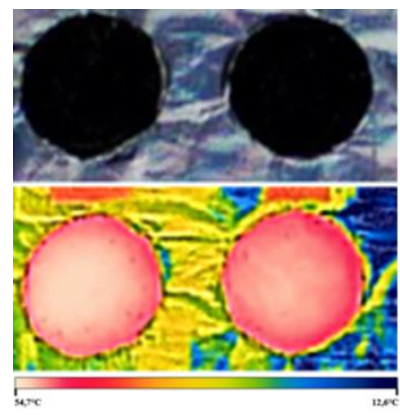

(b)

A Erro! Fonte de referência não encontrada. (a) apresenta as variações da temperatura superficial superior nos corpos de prova. Percebe-se que as temperaturas atingiram valores superiores a $60^{\circ} \mathrm{C}$ nos dois traços investigados. Em pesquisa conduzida por Asaeda, Ca e Wake (1996), as temperaturas superficiais no revestimento asfáltico foram superiores a $60^{\circ} \mathrm{C}$ às $14 \mathrm{~h}$. No entanto, as temperaturas no concreto convencional e no solo exposto não ultrapassaram $39^{\circ} \mathrm{C}$ e $38^{\circ} \mathrm{C}$, respectivamente. Ratifica-se, portanto, que o revestimento asfaltico é um dos grandes responsáveis pelo aquecimento do ar nas áreas urbanas por meio de trocas térmicas sensíveis (CALLEJAS; DURANTE; ROSSETI, 2015).

Ao se comparar o traço T1 (de referência) com o T2 (5\% de PET), nota-se redução da temperatura da face superior em média de $1,2^{\circ} \mathrm{C}$ do traço $\mathrm{T} 2$ em relação ao $\mathrm{T} 1$, com maior diferença alcançada às $14 \mathrm{~h} 30 \mathrm{~min}$ de $1,77^{\circ} \mathrm{C}$. $\mathrm{O}$ menor aquecimento da mistura T2 é benefico uma vez que fluxo de calor sensível transferido para o ar nas áreas pavimentadas é proporcional à temperatura superficial do revestimento e a do ar. 


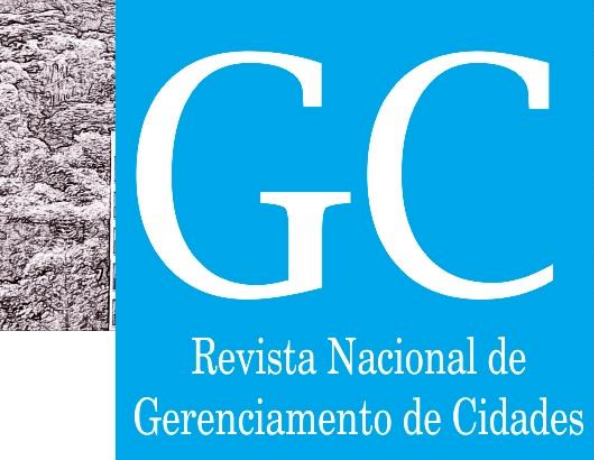

A Erro! Fonte de referência não encontrada. (b) ilustra as variações da temperatura superficial inferior nos corpos de prova, com redução da temperatura à medida que se incorporou os flakes de PET. Notou-se redução da temperatura da face inferior em média de $2,0^{\circ} \mathrm{C}$ do traço $\mathrm{T} 2 \mathrm{em}$ relação ao $\mathrm{T} 1$, com maior diferença alcançada às $11 \mathrm{~h} 30 \mathrm{~min}$ de $2,40^{\circ} \mathrm{C}$. Este fato indica que o traço $\mathrm{T} 2$ pode ser capaz de armazenar menor energia calorífica que o traço sem incorporação de PET.

\subsubsection{Fluxo de Calor Conduzido nos revestimentos}

Ao analisar o comportamento da temperatura superficial nas faces superiores e inferiores dos corpos de prova (Erro! Fonte de referência não encontrada. (a)), nota-se que o traço T2 apresentou valores inferiores ao T1 (referência), o que indica que o corpo de prova de referência tende a perder mais calor para o meio do que o T2 pelo processo de transferência de calor por irradiação e conveção com o ar atmosferico. Isso implica em uma menor quantidade de calor a ser transferida por condução. Logo, era de se esperar, por esta razão, que os corpos de prova T1 apresentassem menor temperatura na face inferior do que os demais, fato este não observado. Assim, conclui-se que o processo de condução ocorreu de forma mais acentuada nos corpos de prova $\mathrm{T} 1$ do que no $\mathrm{T} 2$, visto as maiores temperaturas observadas na face inferior do corpo de prova.

Figura 4: (a) Temperatura superficial na face superior e inferior e (b) Diferença de temperatura $(\Delta T)$ entre as faces dos corpos de prova T1 e T2

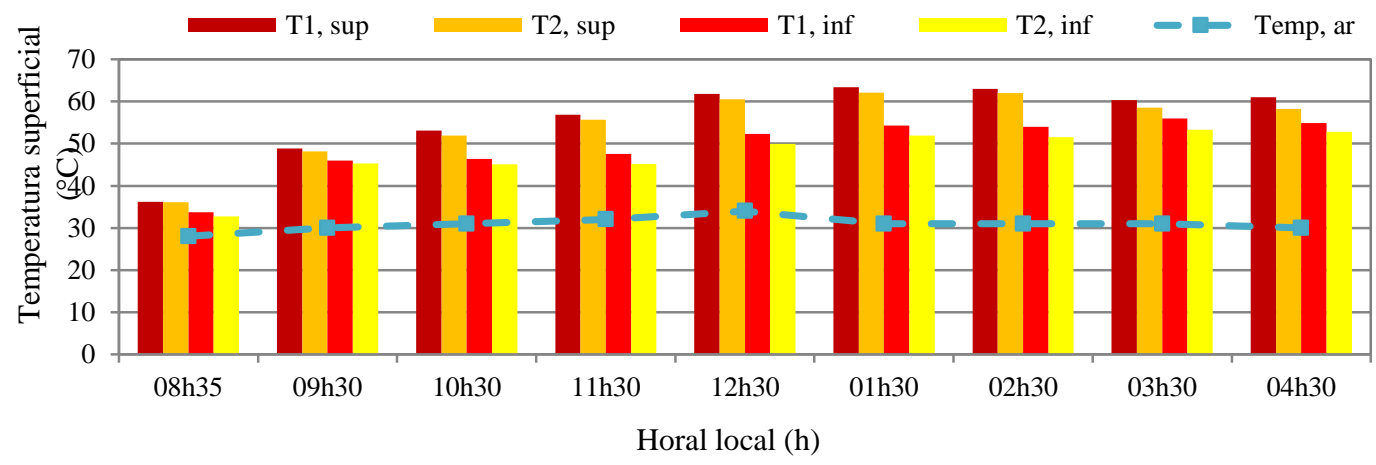

(a) 


\section{Revista Nacional de}

Gerenciamento de Cidades

Figura 5: Fluxo de calor armazenado (eixo principal) e perceção térmica predita pelo UTCI (eixo secundário) estimado nos corpos de prova

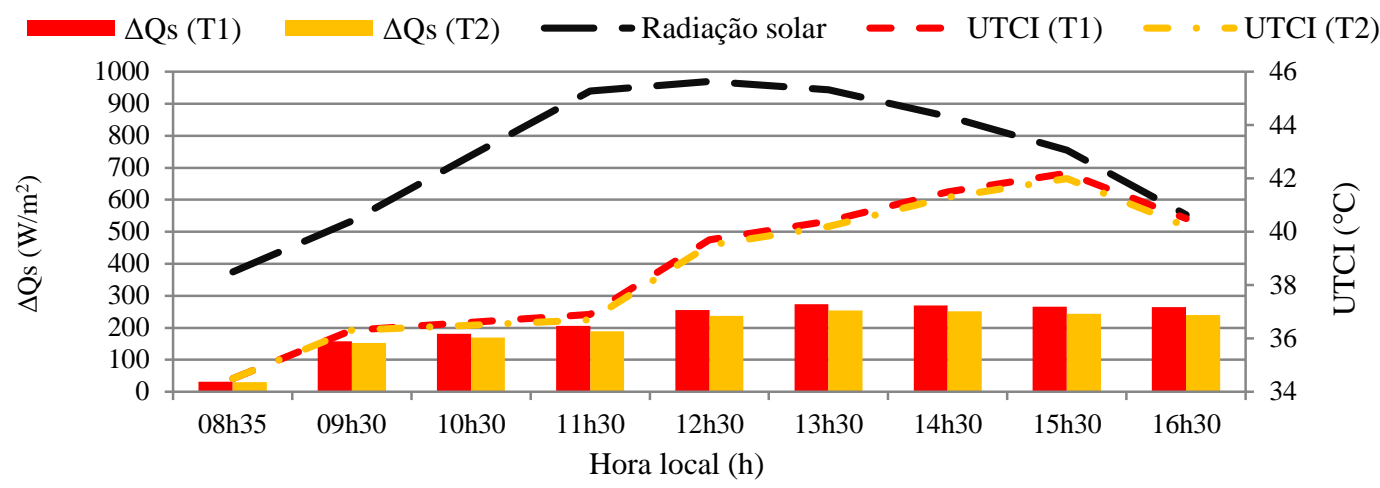

\subsubsection{Sensação Térmica Predita por meio índice térmico}

A percepção térmica derivada do UTCI se eleva à medida que a radiação solar incide no pavimento e eleva sua temperatura (Figura 5, eixo secundário). De acordo com a escala estabelecida para regiões de clima tropical por Borges, Callejas e Durante (2020), a perceção dos pedestres trafegando sobre tais revestimentos sob as condições ambientais registradas durante os ensaios termográficos, se enquadram até às 8 h30min como "moderado estresse ao calor" (faixa de 28,5 a $36^{\circ} \mathrm{C}$ ), enquanto nas demais horas como "forte estresse ao calor" (faixa de 36 a $43^{\circ} \mathrm{C}$ ), indiferentemente do tipo de traço considerado. Os valores corroboram com Nince et al. (2013), que aferindo a sensação térmica sobre o concreto e o asfalto, das 10 às $17 \mathrm{~h}$, constataram índices de sensação térmica de até $43^{\circ} \mathrm{C}$ de UTCI para pedestres.

A redução média horária observada no UTCl, no traço T2 em relação ao traço T1, é de apenas 0,15 ․ C UTCI, o que demonstra que sobre este aspecto, a adição de flakes de PET as mistura em pouco contribui para a redução da sensação térmica dos pedestres, devendo outras alternativas serem utilizadas, como a modificação do índice de reflexão dos pavimentos seja por meio da modificação de sua cor escura para mais clara (aditivos a mistura) ou por meio de tintas refletoras, como proposto por Gartland (2010).

\section{CONSIDERAÇÕES FINAIS}

O traço convencional de CBUQ apresentou desempenho mecânico satisfatório, com $892 \mathrm{kgf}$ de estabilidade e 1,08MPa de resistência a tração, sendo os limites mínimos para estes dois parâmetros $500 \mathrm{kgf}$ e 0,65 MPa, respectivamente. O desempenho mecânico do traço T2 (com substituição parcial de 5\%) mostrou-se inferior ao CBUQ convencional, porém, ainda atendeu a aos requisitos mínimos normativos. Este traço atingiu $632 \mathrm{kgf}$ de estabilidade, 0,79 MPa de resistência à tração e parâmetros volumétricos adequados às misturas asfálticas de rolamento. 


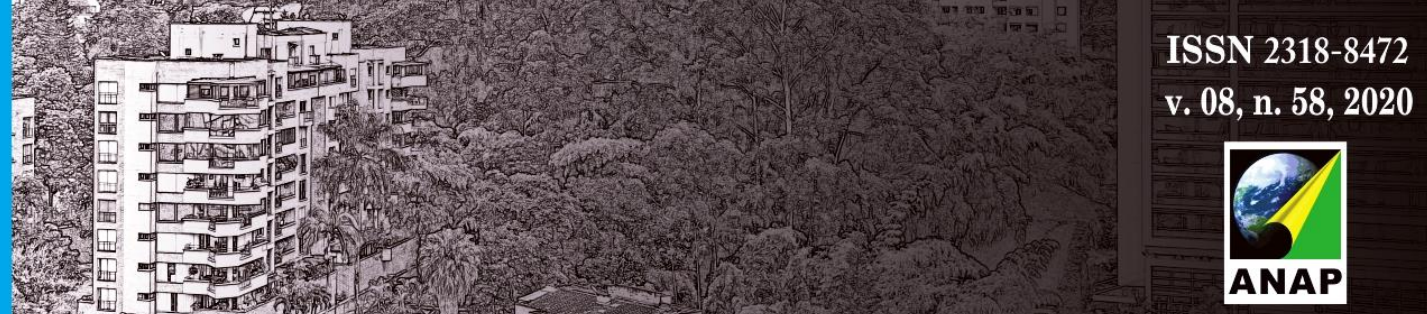

Revista Nacional de

Gerenciamento de Cidades

Para os traços T3 e T4 (com substituição parcial de 10\% e 15\%, respectivamente), os parâmetros volumétricos mostraram-se insatisfatórios para os limites estabelecidos pelas normas DNER-ME 031/2006 e DNER-ME 043/1995. Por este motivo, optou-se por não realizar os ensaios térmicos nos corpos de prova desses traços. Ademais, observou-se uma redução na densidade média destes traços, ocasionada pelos flakes de PET, o que prejudicou o desempenho mecânico destas misturas. Embora ambas as misturas tenham atingido o valor mínimo esperado para estabilidade, sendo $565 \mathrm{kgf}$ e $526 \mathrm{kgf}$, respectivamente para o traço T3 e T4, o CBUQ com 15\% de incorporação de PET obteve apenas $0,54 \mathrm{MPa}$ de resistência à tração, enquanto o traço com $10 \%$ de PET atingiu $0,73 \mathrm{MPa}$.

Quanto aos ensaios térmicos, o traço T2 apresentou o melhor desempenho em relação à temperatura superficial na face superior do corpo de prova, com média de aproximadamente $1,2^{\circ} \mathrm{C}$ a menos que o traço de referência. Verificou-se que a propagação de calor na mistura T2 se reduziu com a incorporação de PET, já que a variação entre as temperaturas das faces superiores e inferiores do corpo de prova T1 aumentou. Isso sugere que a adição de resíduos de PET na mistura asfáltica reduziu o coeficiente de condutividade térmica do CBUQ.

O fluxo de calor armazenado nos corpos de prova se aproximou dos determinados em campo, sendo as menores taxas observadas no traço $\mathrm{T2}$, com valor médio $7,8 \%$ inferior ao traço T1. Este comportamento é benefico uma vez que um menor estoque de energia dentro do revestimento ocasiona menor dissipação de calor durante o período noturno, evitando que a atmosfera dentro do meio urbano permaneça mais aquecida em relação ao seu entorno rural.

A percepção térmica, estimada por meio do UTCl é resultado, entre outros fatores, das elevadas temperaturas superficiais identificadas em nos traços $\mathrm{T} 1$ e T2, que chegaram a alcançar valores superiores a $60^{\circ} \mathrm{C}$. Não se observou diferenças na percepção térmica predita pelo índice UTCI que indicassem que a incorporação de PET seja benéfica sob ponto de vista de estresse térmico ao calor. Nesse sentido, outras alternativas técnicas devem ser adotadas para reduzir o nível de estresse térmico dos pedestres que trafegam sobre os pavimentos asfálticos.

Conclui-se, portanto, que a incorporação de $5 \%$ de flakes de PET em substituição ao agregado miúdo resultou em melhorias no desempenho térmico do $C B \cup Q$, diminuindo a condutibilidade térmica do material e mantendo as propriedades mecânicas dentro dos limites estabelecidos pelas normas. Dessa forma, trata-se de uma opção tecnicamente viável para a destinação destes resíduos, principalmente em vias localizadas dentro do meio urbano, uma vez que a redução de armanezamento calorífico proporcionada pela adição de PET dentro dos revestimentos asfálticos contribui para a redução do fenômeno da ICU.

\section{REFERÊNCIAS BIBLIOGRÁFICAS}

ABNT - Associação Brasileira de Normas Técnicas. NBR 51 - Agregado graúdo - Ensaio de abrasão “Los Angeles”, Rio de Janeiro, 2001.

2002.

NBR 52 - Agregado miúdo - Determinação da massa específica e massa específica aparente, Rio de Janeiro, 

